\title{
The ant-parasitizing genus Pseudacteon Coquillett (Diptera: Phoridae) from China with description of three new species
}

\author{
Guang-Chun Liu, Jian-Feng Wang \& Yun-Long Cai
}

Liu, G.-C., Wang, J.-F. \& Cai, Y.-L. 2013: The ant-parasitizing genus Pseudacteon Coquillett (Diptera: Phoridae) from China with description of three new species. - Entomol. Fennica 24: 53-58.

The ant-parasitizing genus Pseudacteon Coquillett is reported for the first time in China. Three new species, P. quadrisetalis Liu \& Cai, sp. n., P. obtusatus Liu \& Cai, sp. n. and $P$. hexosetalis Liu \& Wang, sp. n., are described and illustrated.

G.-C. Liu, J.-F. Wang, Y.-L. Cai, Liaoning Key Laboratory of Urban Integrated Pest Management and Ecological Security, Shenyang University, No. 21 South Wanghua Street, Dadong District, Shenyang 110044, China; *Corresponding author'se-mail:liugc@yahoo.cn

Received 16 April 2012, accepted 1 November 2012

\section{Introduction}

The genus Pseudacteon Coquillett is a group of phorid flies that attack and parasitize ants, causing decapitation of the host workers during pupation. These flies have recently received extensive attention because of their potential to control introduced fire ants (Solenopsis Westwood), which have caused serious problems in the southern United States, Australia and China (Zhang et al. 2007). Due to intensive studies, at present 65 Pseudacteon species have been described worldwide, of which 52 from the Neotropical and Nearctic Regions. In the Palaearctic Region, 12 species have been reported, which are covered by Disney (2000), Disney and Michailovskaya (2000) and Disney and Withers (2009). Pseudacteon javensis (Brues) is the only species reported from the Oriental Region (Brues 1915) and $P$. crinifer Beyer is distributed only in the Australian Region (Beyer 1966).

China belongs to the Palaearctic and Oriental Regions and the knowledge of Pseudacteon is still limited. No species of the genus was known to occur in China prior to this study. During the survey of the parasitizing phorid flies in the mainland China, we found a series of specimens of Pseudacteon species. In the present paper, three new species are described and illustrated.

\section{Material and methods}

The specimens were collected with nets and preserved in $75 \%$ ethyl alcohol in vials. From each specimen, head, legs, wings and abdomen were detached. The abdomen was left in $10 \% \mathrm{KOH}$ for several hours and then transferred in glycerin for further study. The other body parts were mounded on slide in Belease Fluid (Disney 2001).

The illustrations were made in Leica DM 2000 compound microscope fitted with a drawing tube. The photos were taken in Olympus BX41 compound microscope and SZX10 stereozoom microscope with charge-coupled device 

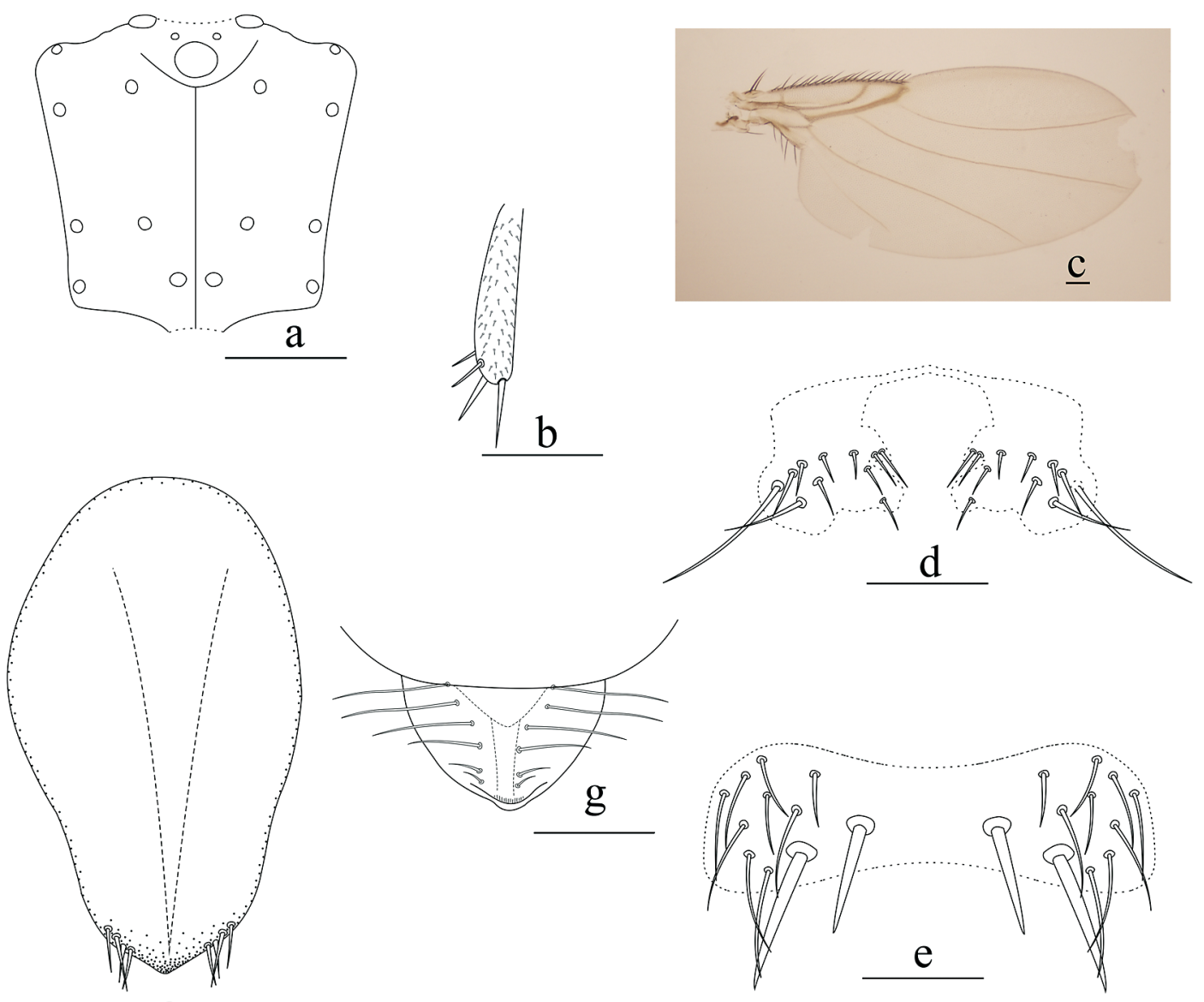

$\mathrm{f}$

Fig. 1. Pseudacteon quadrisetalis Liu \& Cai, sp. n. - a. frons. - b. palpus. - c. wing. - d. tergite VI. - e. sternite VI. - f. dorsal plates. $-\mathrm{g}$. part of ventral plate. Scale: $0.1 \mathrm{~mm}$.

(CCD) imaging system. The terminology mainly follows Disney (2000). Measurements are given in millimeters.

The type specimens are deposited in Liaoning Key Laboratory of Urban Integrated Pest Management and Ecological Security, Shenyang University, Shenyang, China.

\section{Descriptions of new species}

\subsection{Pseudacteon quadrisetalis Liu \& Cai, sp. n. (Fig. 1)}

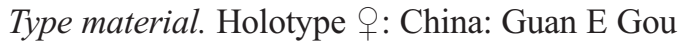
$\left(33.92^{\circ} \mathrm{N}, \quad 104.29^{\circ} \mathrm{E} ; 2,478 \mathrm{~m}\right)$, Tanchang County, Gansu. 10.VIII.2011, Cai Yun-Long leg.
Paratypes: 19 , same data as holotype; 290 , Qiu Jia $\mathrm{Ba}\left(32.92^{\circ} \mathrm{N}, 104.32^{\circ} \mathrm{E} ; 2,270 \mathrm{~m}\right)$, Wen County, Gansu, 7.VIII.2011, Cai Yun-Long leg.

Description. Female. Head. Frons blackish brown, with about 20 hairs plus 2 on ocellar triangle and very dense fine microsetae. Frons with 2 pairs of supra-antennal bristles, lower pair proclinate and the upper one reclinate. Upper pairs are as high as the anterolateral bristles (Fig. 1a). Flagellomere 1 pear-shaped and arista light brown. Palpus pale, very lightly tinged brown, and not enlarged, with 4 bristles at apical half (Fig. 1b).

Thorax. Brown with a bare mesopleuron. Each side of scutum with a small humerical bristle, two notopleurals, a pre-alar, a post-alar and a pre-scutellar dorsocentral bristle. Scutellum with 


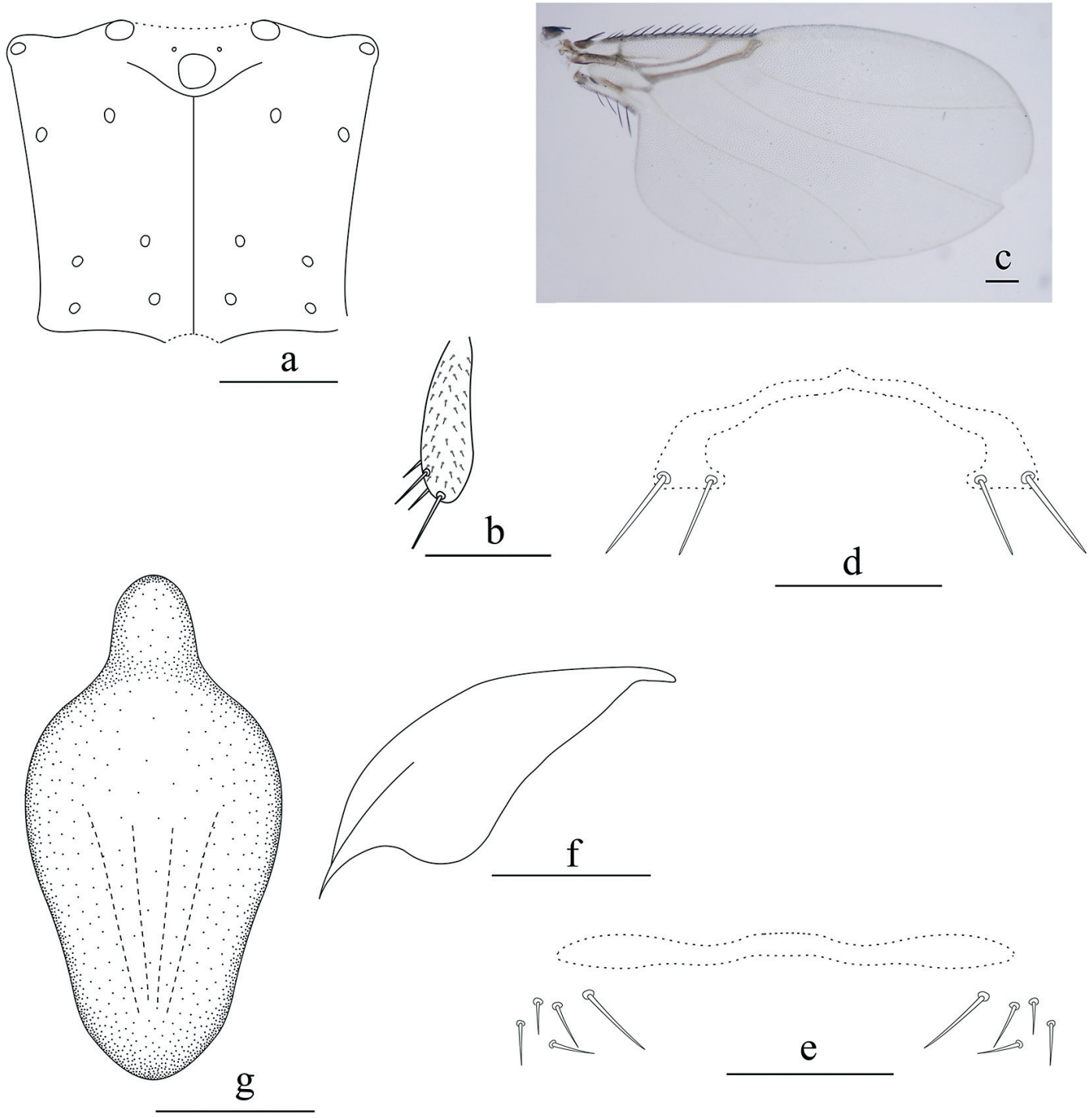

Fig. 2. Pseudacteon obtusatus Liu \& Cai, sp. n. - a. frons. - b. palpus. - c. wing. - d. tergite VI. - e. sternite VI. $-\mathrm{f}$. ovipersitor sheath in laterial view. $-\mathrm{g}$. dorsal plate. Scale: $0.1 \mathrm{~mm}$.

an anterior pair of shorter bristles and a longer posterior pair. Legs yellowish brown. Front tibia without palisade. Mid tibia with near-dorsal longitudinal hair palisade extending about two thirds of length and comprising 35-40 modified hairs. Hind femur with 6-8 long hairs below basal half and 6-8 long anteroventral hairs in outer half. Hind tibia with $8-10$ differentiated posterodorsals before the stronger pre-apical bristles. The palisade of hind tibia completed, sinuous. Wing length $1.68 \mathrm{~mm}$. Costal index 0.39. Costal ratio 1.96:1. Costal cilia $0.08 \mathrm{~mm}$ (Fig. 1c). Haltere brown.

Abdomen. Tergites brown with minute sparse hairs only. Tergites II-V all very much broader than long, but progressively narrowing from tergite II backwards. Tergite VI variable with some bristles (Fig. 1d). Venter greyish brown and segments 1-5 bare. Sternite VI blackish brown, clearly defined, with 4 very strong, pin-shaped bristles and some long, bristle-like hairs (Fig. 1e). Ovipositor sheath brown, downward. Dorsal 
plate arched, with 3-4 short hairs on sub-apex of each side (Fig. 1f). Ventral plate with 12-16 fine, long and transverse-inclined hairs arranged in two longitudinal rows (Fig. 1g).

Male. Unknown.

Etymology. The name refers to the characters of abdominal sternite VI.

Remarks. The new species is easily recognized in having 4 very strong pin-shaped bristles on abdominal sternite VI and transverse-inclined long hairs on ventral plate of ovipositor sheath. In the key to European Pseudacteon (Disney \& Withers 2009), the species runs to couplet 6, to $P$. fennicus Schmitz. It differs from the latter by 4 very strong, pin-shaped bristles on sternite VI and 12-16 fine, long and transverse-inclined hairs on ventral plate of ovipositor sheath. In the key to Pseudacteon of the Russian Far East (Disney \& Michailovskaya 2000), the species runs to couplet 4, to the putative female of $P$. pullum Michailovskaya, but it is different in having 3540 modified hairs of mid tibial hair palisade.

\subsection{Pseudacteon obtusatus Liu \& Cai, sp. n. (Fig. 2)}

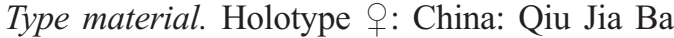
$\left(32.92^{\circ} \mathrm{N}, 104.32^{\circ} \mathrm{E} ; 2,270 \mathrm{~m}\right)$, Wen County, Gansu, 7.VIII.2011, Cai Yun-Long leg. Paratypes: $3 ㅇ+$, same data as holotype.

Description. Female. Head. Frons yellowish brown, with 20 hairs plus 2 on ocellar triangle and very dense fine microsetae. Frons with 2 pairs of supra-bristles, lower pair proclinate and upper one reclinate; upper pair higher than anterolateral bristles (Fig. 2a). Flagellomere 1 pear-shaped and arista light brown, with 4 bristles at apical half. Palpus pale, very lightly tinged brown, and not enlarged (Fig. 2b).

Thorax. Brown with a bare mesopleuron. Each side of scutum with a small humerical bristle, two notopleurals, a pre-alar, a post-alar and a pre-scutellar dorsocentral bristle. Scutellum with an anterior pair of shorter bristles and a longer posterior pair. Legs yellow. Front tibia without palisade. Mid tibia with near-dorsal longitudinal hair palisade extending about two thirds of length and comprising 18-20 modified hairs. Hind femur with 6 long hairs below basal half and 4 long anteroventral hairs in outer half. Hind tibia with 8 differentiated posterodorsals before stronger preapical bristles. Wing length $1.36 \mathrm{~mm}$. Costal index 0.38. Costal ratio 1.87:1. Costal cilia 0.06 mm (Fig. 2c). Haltere brown.

Abdomen. Tergites brown with minute sparse hairs only. Tergites II-V all very much broader than long, but progressively narrowing from tergite II backwards. Tergite VI reduced to a narrow anterior strip in middle but each lateral side bearing 2 bristle-like hairs at rear margin (Fig. 2d). Venter greyish brown and segments 1-5 bare. Sternite VI brown, reduced to a narrow strip in middle, bearing 2 short bristles and 2-3 hairs on each ill-defined side (Fig. 2e). Ovipositor sheath brown, downward (Fig. 2f). Dorsal plate with obtuse process on base and with about 10 hairs on sub apex (Fig. 2g). Ventral plate bare.

Male. Unknown.

Etymology. The species name refers to the characters of the ovipositor sheath.

Remarks. In the key to European Pseudacteon (Disney 2009), the species runs to couplet 6, to $P$. fennicus Schmitz. It differs from the latter in having an obtuse process on dorsal plate of ovipositor sheath. In the key to Pseudacteon of the Russian Far East (Disney \& Michailovskaya 2000), the species runs to couplet 4 , to the putative female of $P$. pullum Michailovskaya, but it is different in having 18-20 modified hairs of mid tibial hair palisade.

\subsection{Pseudacteon hexasetalis Liu \& Wang, sp. n. (Fig. 3)}

Type material. Holotype ${ }_{+}$: China: Mt. Daming $\left(23.28^{\circ} \mathrm{N}, 108.26^{\circ} \mathrm{E} ; 800 \mathrm{~m}\right)$, Guangxi, 10.VIII. 2011, Feng Dian-Xing and Wang Jian-Feng leg.

Description. Female. Head. Frons yellowish brown, with 20 hairs plus 2 on ocellar triangle and very dense fine microsetae. Frons with 3 pairs of supra-antennal bristles, lower pair is preclinate, middle and upper ones reclinate; upper pair higher than anterolateral bristles (Fig. 3a). Flagellomere 1 pear-shaped and arista light brown. Palpus pale, very lightly tinged brown, and not enlarged (Fig. 3b).

Thorax. Brown, with a bare mesopleuron. Each side of scutum with a small humerical bristle, two notopleurals, a pre-alar, a post-alar and a 

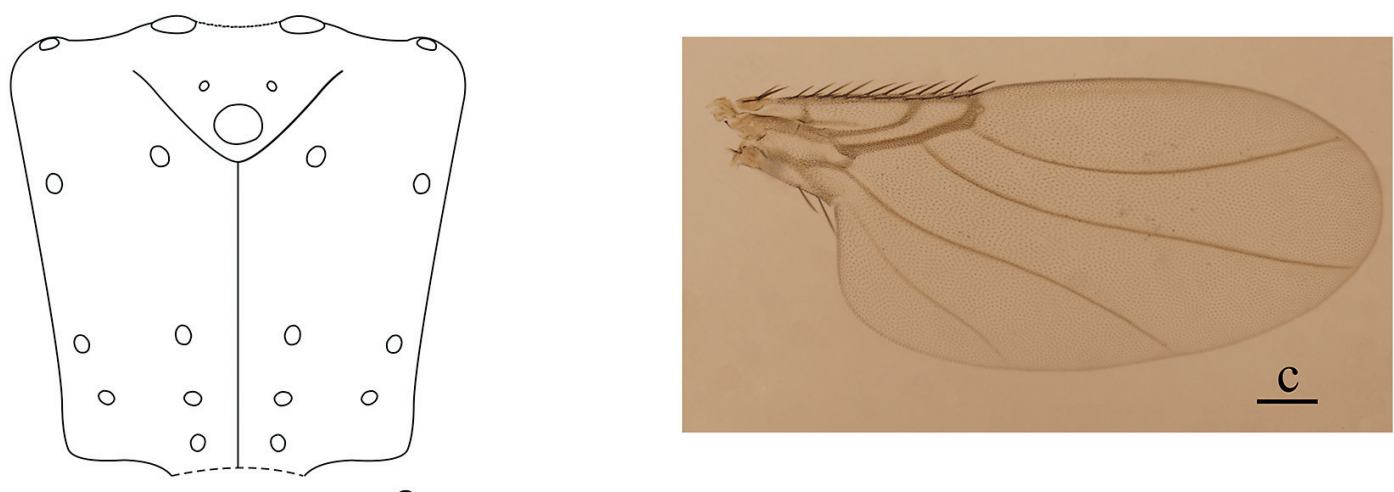

a
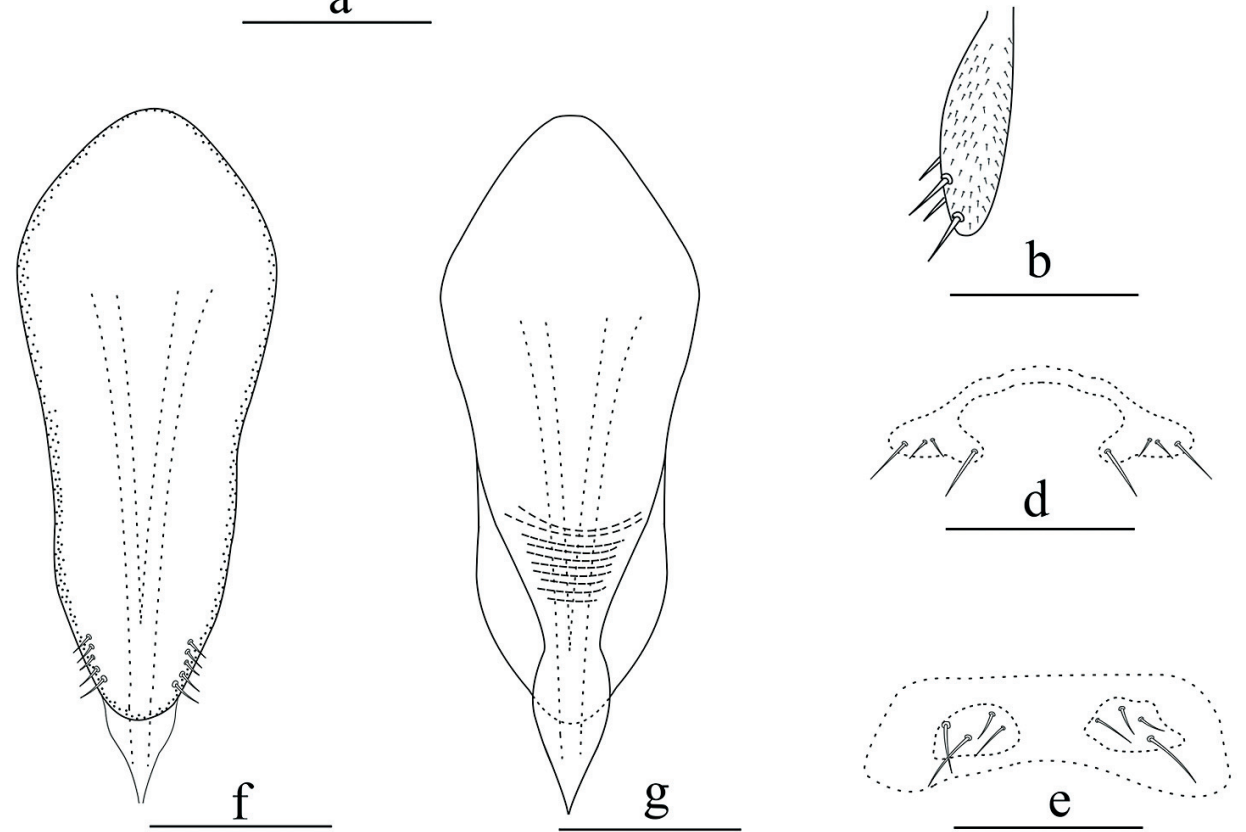

Fig. 3. Pseudacteon hexasetalis Liu \& Wang, sp. n. - a. frons. - b. palpus. - c. wing. - d. tergite VI. - e. sternite VI. - f. dorsal plate. - g. ventral plate. Scale: $0.1 \mathrm{~mm}$.

pre-scutellar dorsocentral bristle. Scutellum with an anterior pair of shorter bristles and a longer posterior pair. Legs yellow. Front tibia without palisade. Mid tibia with near-dorsal longitudinal hair palisade extending about two thirds of length and comprising 19 modified hairs. Hind femur with 6 long hairs below basal half and 4 long anteroventral hairs in outer half. Hind tibia with 8 differentiated posterodorsals before the stronger pre-apical bristles. Wing length $1.02 \mathrm{~mm}$. Costal index 0.36. Costal ratio 1.44:1. Costal cilia 0.05 mm (Fig. 3c). Haltere brown.

Abdomen. Tergites brown with minute sparse hairs only. Tergites II-V all very much broader than long, but progressively narrowing from tergite II backwards. Tergite VI with 3-4 short bristles on each side (Fig. 3d). Venter greyish brown and segments 1-5 bare. Sternite VI blackish brown, with some weak bristles and hairs (Fig. 3e). Ovipositor sheath fine, yellowish brown. Dorsal plate with 5 short hairs on sub-apex (Fig. 3f). Ventral plate pointed, arrow-shaped, middle part dark (Fig. 3g).

Male. Unknown.

Etymology. The species name refers to the chaetotaxy of frons.

Remarks. The new species is easily distinguished from other species by three pairs of su- 
pra-antennal bristles and the characters of ovipositor sheath.

Acknowledgements. The research was supported by the National Natural Science foundation of China (No. 31071965).

\section{References}

Beyer, E. M. 1966: Neue und wenig bekannte Phoridae, zumeist aus dem Bishop Museum, Honolulu. — Pacific Insects 8(1): 165-217.

Brues, C. T. 1915: Some new Phoridae from Java. — New York Entomological Society 23(3): 184-193.
Disney, R. H. L. 2000: Revision of European Pseudacteon Coquillett (Diptera, Phoridae). — Bonner zoologische Beitraege 49: 79-91.

Disney, R. H. L. 2001: The preservation of small Diptera. - Entomologist's Monthly Magazine 137: 155-159.

Disney, R. H. L. \& Michailovskaya, M. V. 2000: New species of Pseudacteon Coquillett (Diptera: Phoridae) from the Far East of Russia. — Fragmenta Faunistica 43: $35-45$.

Disney, R. H. L. \& Withers, P. 2009: A new species of Pseudacteon Coquillett (Diptera, Phoridae) and a new key to the European species. - Fragmenta Faunistica 52: 1-12.

Zhang R. Z., Li, Y. C., Liu, N. \& Porter, S. D. 2007: An overview of the red imported fire ant (Hymenoptera: Formicidae) in mainland China. — Florida Entomologist 90(4): 723-731. 